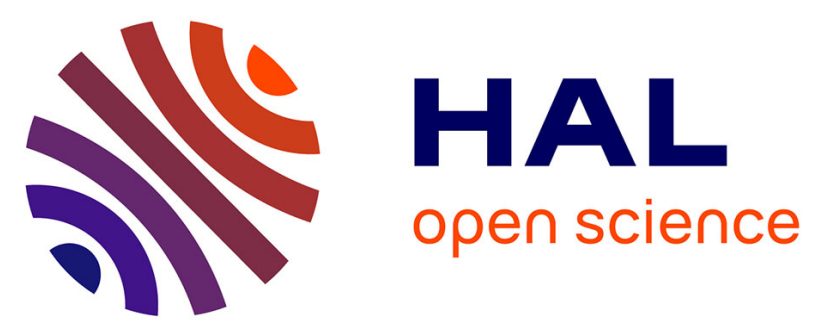

\title{
Insights from User Experience Research in the Factory: What to Consider in Interaction Design
}

\author{
Daniela Wurhofer, Verena Fuchsberger, Thomas Meneweger, Christiane \\ Moser, Manfred Tscheligi
}

\section{- To cite this version:}

Daniela Wurhofer, Verena Fuchsberger, Thomas Meneweger, Christiane Moser, Manfred Tscheligi. Insights from User Experience Research in the Factory: What to Consider in Interaction Design. 4th IFIP 13.6 Working Conference on Human Work Interaction Design (HWID), Jun 2015, London, United Kingdom. pp.39-56, 10.1007/978-3-319-27048-7_3 . hal-01371785

\section{HAL Id: hal-01371785 \\ https://hal.inria.fr/hal-01371785}

Submitted on 9 Nov 2016

HAL is a multi-disciplinary open access archive for the deposit and dissemination of scientific research documents, whether they are published or not. The documents may come from teaching and research institutions in France or abroad, or from public or private research centers.
L'archive ouverte pluridisciplinaire HAL, est destinée au dépôt et à la diffusion de documents scientifiques de niveau recherche, publiés ou non, émanant des établissements d'enseignement et de recherche français ou étrangers, des laboratoires publics ou privés.

\section{(c)(1)}

Distributed under a Creative Commons Attribution| 4.0 International License 


\title{
Insights from User Experience Research in the Factory: What to Consider in Interaction Design
}

\author{
Daniela Wurhofer, Verena Fuchsberger, Thomas Meneweger, \\ Christiane Moser and Manfred Tscheligi \\ Center for Human-Computer Interaction, \\ Christian Doppler Laboratory "Contextual Interfaces", \\ University of Salzburg, Salzburg, Austria \\ \{firstname.lastname $\}$ @sbg.ac.at
}

\begin{abstract}
During the past few years we investigated humans' work in a semiconductor factory, both in relation to digital and non-digital artifacts. With this paper, we provide an overview of aspects that are relevant in production environments. In particular, we present factors accounting for workers' experience as well as influences on their user experience (UX). Based on a meta-interpretation approach, we analyzed our previous studies on the basis of publications that presented our previous research results. In total, we annotated 21 publications, which reported results from qualitative (e.g., ethnographies, interviews) and quantitative approaches (e.g., questionnaires). Overall, this work contributes to an orientation for designers and researchers regarding the interplay between user, system and context in a factory environment by pointing out relevant aspects of and influences on workers' experiences.
\end{abstract}

Keywords: factory, production environment, user experience, interaction, design, context, user, system, work

\section{Motivation}

Research on user experience (UX) is often highlighting the relevance of the context, in which the interaction with an artifact takes place. Consequently, rich descriptions of contexts are needed, but according studies are still rare [3]. Many studies only focus on particular aspects of experiences, but widely ignore the multidimensionality of UX and the interrelationship of UX dimensions in specific contexts. Further, UX research has primarily been focusing on art and consumer products, while lacking devotion to work contexts [3]. This might be due to access restrictions, i.e., research faces a variety of limitations when trying to investigate competitive or safety-critical environments (e.g., [4], [14]). Another reason could be that the potential of performing experience research is less obvious in a factory context [25].

This paper represents an attempt to summarize a series of different studies in the context of a semiconductor factory in order to identify relevant aspects with regard to UX (i.e., workers' experience). We aim to provide an orientation 
for researchers and designers by creating awareness that workers' experience is crucial for their well-being and performance. We present aspects that account for workers' experiences in a factory context which can be researched and designed for, reflecting that workers' experience is multifaceted. In order to better understand this context with regard to UX, we conducted a range of qualitative and quantitative studies. These provided us with a comprehensive understanding of workers' routines and experiences and helped us to identify aspects that are of particular relevance for UX in the factory (e.g., trust, stress $)^{1}$.

In this paper, we provide an overview of relevant factors, which we found in our previous work. These factors include aspects of the workers' experience when interacting with systems in such a context, as well as influences on workers' UX in form of system properties (e.g., efficiency), user characteristics (e.g., attitude), as well as characteristics of the social (e.g., hierarchy) and physical (e.g., space) context. Although these aspects are interrelated, they address specific notions of users' interactions that need to be taken into account in the design of interactive systems for the factory.

The paper is structured as follows. After motivating our work, we provide background information about research in the factory in general, as well as research on UX in the factory in particular. Then, we present our research approach by introducing the study context, method and procedure, as well as the materials used. Next, we present our findings according to identified UX factors as well as influences on UX. We then discuss our insights with regard to particularities of the factory context, design, methodology, UX factors, value of UX research, specifics of the use case, as well as opportunities and challenges. Finally, we conclude the paper and provide an outlook for future work.

\section{Background}

In this section, we point out related work in the area of UX and factory research. This provides a basis to better understand our research with regard to the specifics of the context (i.e., factory) and the theoretical grounding of our work (i.e., UX).

\subsection{Research in the Factory}

In general, industrial contexts pose a variety of challenges and restrictions, for instance, fieldwork must not impact work practices [4], [37], [40]. For decades, scientists have been occupied with investigating factory work from a point of view of classical or social psychology (e.g., [6]). A great number of research addresses health or safety aspects as well as ergonomics. Regarding humans' interaction with systems, the factory context has been less prominent in HCI research and publications. Few material can be found that puts factory workers into the focal point of attention when designing interfaces. In the beginning of the 1990s, an

\footnotetext{
${ }^{1}$ in the following considered as "UX factors"
} 
IEEE Colloquium was held on "HCI: Issues for the Factory", dealing with the psychological basis for computer system design, operator support systems and industrial inspection [15]. This colloquium, however, remained a unique event and was not continued in the following years. One of the few pointing out the importance of investigating new technologies in the factory context is Fallman [10], considering the industrial use of information technology (IT) as "paradigm shift".

Our own research is primarily concerned with UX in challenging contexts, one of them being production environments (e.g., [25], [37], [41]). As part of a national large scale project - the Christian Doppler Laboratory "Contextual Interfaces" (CDL) [11] - we examine contextual interaction from qualitative, constructional, and methodological viewpoints in different application areas. Apart from basic research activities focusing on methods and tools for contextual research, the laboratory explores the contexts "car" and "factory" from these three perspectives. In the context "factory", we conduct research on UX in a semiconductor fabrication plant, where microchips are produced. There, we investigate, design, develop and prototype elements of novel human-centered, integrated, production interface systems. These systems are based on the intelligent cooperation between humans and (intelligent) computing systems, enabling enhanced user experience qualities. By this research, we advance the field of situated interface development (including "robotic interfaces") as well as the area of contextual user experience.

\subsection{Research on (Workers') User Experience}

Researchers still stress the need for a precise understanding of UX as well as a comprehensive formulation of the concept and its constituting factors (e.g., [12], [19], [24]), covering a range of contexts and situations. According to McCarthy and Wright [20], experience is constructed out of the interplay of the human and the technology in a situation. Thus, experiences are dynamic, situated, and never the same. McCarthy and Wright emphasize the situatedness and uniqueness of experience and object reductions of experience into separate areas of study (i.e., holistic approach on experience). In contrast, Hassenzahl and colleagues [13] suggest categorizing experiences on the basis of psychological needs and link them to affect and product perception. They highlight the need for some kind of generalization of experiences in order to be useful for HCI, and for designing interactive products (i.e., reductionistic approach on experience). In our research, we acknowledge the situatedness of interactions, which we take into account by investigating very specific, situated interactions. At the same time, we aim to generalize our findings in the sense that we summarize and cluster the observations to provide an overview of relevant aspects in order to open up the research and design space of production environments.

Especially in industrial domains and production environments, the value of UX research may not be obvious at a first glance. There are still many companies that do not focus on their workers' experience, or do not properly consider it [2]. Following Alben [1], we consider UX as being comprised of all the aspects of how 
people interact with an interactive artifact; e.g., how it feels in the hands, how well it is understood, how it is perceived during interaction, how well it serves their purposes, and how well it fits the context of use. With regard to the work domain and in particular factory work, with "people" we refer to factory workers. "Interactive artifacts" comprise all systems, devices, equipment and interfaces workers have to interact with regarding daily work. According to Kaasinen et al. [16], the key prerequisite for experience-driven design is to define what experience to design for. UX factors (e.g., from existing frameworks) can be employed as the basis for setting UX goals for design. The main challenges are to create a solid value argumentation for focusing on workers' experiences and showing the link between the monetary value it can create [38]. According to [38], positive experiences with the technology are for example related o the user's efficiency, work satisfaction, and professional pride. Similarly, on a customer level, there could be effects on productivity, competitiveness, or brand image. Better UX may lead to reduced learning time, reduced sick leaves, or more satisfied users in general. Satisfaction may reduce employee turnover and support the customers image as an attractive employer. Further, UX research in the industrial domain can act as a differentiating factor by offering competitive advantage.

UX research is closely linked to specific challenges. For example, measuring UX or investigating which characteristics contribute to a positive UX may be a difficult endeavor. In particular, this affects research on UX in production environments, as the context poses a variety of further constraints and challenges that increase the complexity of such investigations. Within the Christian Doppler Laboratory "Contextual Interfaces" (nationally funded for seven years), we address this issue [11]. There, we aim to research contextual interaction from different viewpoints, e.g., understanding users in contexts or designing interfaces and interactions for challenging environments. For example, we already stressed the importance of UX in the factory [25] and provide initial insights on workers' everyday experiences and contextual influences on it [44].

\section{Approach}

To provide comprehensibility and traceability of our research, the following section gives details about the context of our study, the methodological set up and procedure, as well as the materials used for the analysis.

\subsection{Study Context: The Semiconductor Factory}

In our work, we collaborate with a semiconductor fabrication plant, where microchips are produced. The overall goal of the semiconductor fabrication plant is a "zerodefect" production of microchips, i.e., ideally there are no defects during manufacturing, as they would be very costly. Consequently, the following aspects are crucial: continuous improvements of the work place, processes, and equipment, fast feedback loops, detection of weak spots, avoidance of redundant work, and ongoing enhancement of wafer quality. The production takes place in 
so called cleanrooms, which are categorized in different micro dust halls. The interaction in a factory is challenging, as the work has to be done quickly and exactly. Human errors can lead to high costs. Furthermore, operators often do have to work together and rely on each other and since a factory often is a closed and special environment, microcosms arise among operators within a factory.

The main challenge for semiconductor manufacturing plants is the coordination of many operators working on different machines to guarantee an efficient production process. As soon as we talk about factory ergonomics like safe, usable, and comfortable interfaces, we are also addressing aspects of UX (e.g., perceived safety). Despite the obvious relevance of UX in the factory, little research has dealt with this issue. This might be partly rooted in the difficulties and limitations of such a context, or due to the fact that the investigation of UX might lead to competitive advantage, and are thus not published for a greater audience. Further, the cleanroom poses several challenges for research, e.g., 24/7/365 production, high complexity of processes, interfaces and interactions, or the need for special equipment, like cleanroom suits.

\subsection{Method \& Procedure}

In order to summarize and cluster UX factors based on our previous work, we drew on the approach of meta-interpretation [39]. Traditional literature reviews give an overview of the field, i.e., they are often descriptive and are rarely able to make sense of what the collection of studies reviewed has to say. In contrast, the meta-interpretation approach of Weed [39] maintains an interpretive epistemology by focusing on the interpretive synthesis of qualitative research (i.e., meaning in context). The meta-interpretation approach is based on the evaluation of eight research methods or approaches that include some form of synthesis (literature review, systematic review, meta-analysis, meta-ethnography, grounded theory, cross-case comparison, secondary analysis of primary data, and interpretive phenomenological analysis).

As suggested by Weed [39], our first step was to identify the overlying topic according to our research goal, namely to identify factors which account for operators' experience in the semiconductor factory. Afterwards, we established the "meaning in context", i.e., we collected an initial set of relevant publications and analyzed their content in terms of the goal of the literature synthesis. Based on this initial analysis, we included further studies and excluded those, which did not fit our objective (e.g., studies that did not address or detail their understanding of UX). The analysis was continued until theoretical saturation was reached, i.e., no further findings regarding UX were identified in the publications (see table 1 for an overview of publications included in the analysis). Finally, we summarized the findings.

\subsection{Overview on Materials Used}

All publications that are mentioned in this subchapter were included into the analysis for this paper (see table 1). In total, we analyzed 21 papers. Thereof, 14 
were published as conference proceedings, 2 as book chapters, and 5 as workshop position papers. The work covered was published between 2010 and 2014, with most of the papers being published in $2012(\mathrm{n}=8)$ and $2013(\mathrm{n}=7)$. In order to provide an overview of how they relate, their origin, objective, or approach is described in the following.

Overall, our theoretical perspective on UX was both holistic and reductionistic. Initially, we followed a holistic perspective on UX in order to get an understanding of the heterogeneity of the contextual constraints and conditions in the cleanroom and the task diversity of different workers (e.g., operators, shift leads, maintainers) in this area. By applying qualitative methods like contextual inquiry, interviews, probing, or creative workshops (e.g., [17], [18], [25], [27], [41], [44]), we gained a comprehensive picture of workers' routines and experiences.

In this early phase of our research, we focused on the uniqueness of experience, aiming to describe individuals' situated experiences in detail. Based on these findings we identified different factors, which play an especially important role in this context (e.g., trust, stress). In later stages of our research, we focused on these selected UX factors to explore them in detail, reflecting the adoption of a reductionistic perspective. In particular, the change of workers' specific experiences over time when introducing new interfaces turned out to be a promising field for future research [8]. For instance, we conducted a study on industrial robots in the cleanroom, where we accompanied the deployment of a new robotic arm over one and a half years [8], investigating changes of the workers' experience. Based on the findings from studies in the cleanroom (e.g., [8], [40]), we also focused on specific UX factors relevant in the factory by conducting lab studies. In terms of human-robot interaction, we studied the role of feedback [30], anthropomorphism [31], training [32], social cues [42], or input modalities and task complexity [33-35]. Furthermore, the studies were the basis for designs and UX prototypes. In these designs, we focused on wearable devices [26], [28], or ambient, persuasive displays in the factory [7], [22], [23], [36].

The diversity of the above listed research activities and studies provided us with a comprehensive framing of UX in the factory and allowed us to identify factors which account for the workers' experience. The next section provides details about our insights regarding workers' experiences in the factory as well as influences on it.

\section{Findings}

In this section, we describe relevant aspects of the interplay between user, system and context regarding workers' experiences in a factory environment. With user we refer to the workers in the factory (e.g., operators, maintainers, shift leads). With system we mean interfaces, devices, or robots, the user has to work with in the factory. Context refers to the physical or social environment in which the factory work is accomplished. Our findings are structured in form of $U X$ factors (i.e., aspects of experience) as well as influences on $U X$ stemming from the user, the system, or the context. 


\begin{tabular}{|c|c|c|c|c|c|}
\hline & Paper Title & Author & Year & $\begin{array}{l}\text { Publication } \\
\text { Type }\end{array}$ & UX Factors Discussed \\
\hline 1 & $\begin{array}{l}\text { Assisting maintainers in the semi- } \\
\text { conductor factory: Iterative co- } \\
\text { design of a mobile interface and a } \\
\text { situated display }\end{array}$ & Buchner et al. & 2013 & \begin{tabular}{|l|} 
Conference \\
Proceedings
\end{tabular} & $\begin{array}{l}\text { * Perceived Workload } \\
\text { * Feeling of Control } \\
\text { * Perceived Usefulness } \\
\text { * Perceived Ease of Use } \\
\text { * Trust }\end{array}$ \\
\hline 2 & $\begin{array}{l}\text { Robots in Time: How User Expe- } \\
\text { rience in Human-Robot Interaction } \\
\text { Changes over Time }\end{array}$ & Buchner et al. & 2013 & Book Chapter & $\begin{array}{l}* \text { Stress } \\
* \text { Perceived Safety }\end{array}$ \\
\hline 3 & $\begin{array}{l}\text { Collaborative Reporting Tools: An } \\
\text { analysis of maintainance activites } \\
\text { in a semiconductor factory }\end{array}$ & Kluckner et al. & 2013 & $\begin{array}{l}\text { Conference } \\
\text { Proceedings }\end{array}$ & $\begin{array}{l}\text { * Perceived Workload } \\
\text { * Perceived Ease of Use } \\
\text { * Satisfaction }\end{array}$ \\
\hline 4 & $\begin{array}{l}\text { Repair Now: Collaboration between } \\
\text { Maintainers, Operators and Equip- } \\
\text { ment in a Cleanroom }\end{array}$ & Kluckner et al. & 2012 & \begin{tabular}{|l} 
Conference \\
Proceedings
\end{tabular} & $\begin{array}{l}\text { * Perceived Ease of Use } \\
\text { * Satisfaction } \\
\text { * Trust }\end{array}$ \\
\hline 5 & $\begin{array}{l}\text { Ambient Persuasion in the Factory: } \\
\text { The Case of the Operator Guide }\end{array}$ & $\begin{array}{l}\text { Meschtscherjakov et } \\
\text { al. }\end{array}$ & 2011 & $\begin{array}{l}\text { Conference } \\
\text { Proceedings }\end{array}$ & * Perceived Workload \\
\hline 6 & $\begin{array}{l}\text { The Operator Guide: An Ambient } \\
\text { Persuasive Interface in the Factory }\end{array}$ & $\begin{array}{l}\text { Meschtscherjakov et } \\
\text { al. }\end{array}$ & 2010 & \begin{tabular}{|l} 
Conference \\
Proceedings
\end{tabular} & $\begin{array}{l}\text { * Stress } \\
\text { * Perceived Usefulness } \\
\text { * Perceived Ease of Use }\end{array}$ \\
\hline 7 & $\begin{array}{l}\text { User Experience Research in the } \\
\text { Semiconductor Factory: A Contra- } \\
\text { diction? }\end{array}$ & Obrist et al. & 2011 & $\begin{array}{l}\text { Conference } \\
\text { Proceedings }\end{array}$ & $\begin{array}{l}* \text { Stress } \\
* \text { Emotions and Feelings }\end{array}$ \\
\hline 8 & $\begin{array}{l}\text { Using Participatory Design to In- } \\
\text { vestigate Technology Usage in the } \\
\text { Cleanroom of a Semiconductor Fac- } \\
\text { tory }\end{array}$ & Osswald & 2012 & $\begin{array}{l}\text { Workshop Po- } \\
\text { sition Paper }\end{array}$ & $\begin{array}{l}\text { * Stress } \\
* \text { Perceived Usefulness }\end{array}$ \\
\hline 9 & $\begin{array}{l}\text { Designing Wearable Devices for the } \\
\text { Factory Rapid Contextual Experi- } \\
\text { ence Prototyping }\end{array}$ & Osswald et al. & 2013 & $\begin{array}{l}\text { Conference } \\
\text { Proceedings }\end{array}$ & $\begin{array}{l}\text { * Perceived Workload } \\
\text { * Perceived Safety }\end{array}$ \\
\hline 10 & $\begin{array}{l}\text { Designing for the Factory: Wear- } \\
\text { able Experience Prototyping for } \\
\text { Idea Communication }\end{array}$ & Osswald et al. & 2012 & $\begin{array}{l}\text { Conference } \\
\text { Proceedings }\end{array}$ & \\
\hline 11 & $\begin{array}{l}\text { I trained the robot: The impact } \\
\text { of pre-experience and execution be- } \\
\text { havior on robot teachers }\end{array}$ & Stadler et al. & 2014 & $\begin{array}{l}\text { Conference } \\
\text { Proceedings }\end{array}$ & $\begin{array}{l}\text { * Perceived Workload } \\
\text { * Perceived Usefulness } \\
\text { * Trust }\end{array}$ \\
\hline 12 & $\begin{array}{l}\text { Anthropomorphism in the Factory - } \\
\text { A Paradigm Change? }\end{array}$ & Stadler et al. & 2013 & \begin{tabular}{|l|} 
Conference \\
Proceedings
\end{tabular} & $\begin{array}{l}\text { * Stress } \\
\text { * Feeling of Control } \\
\text { * Performance Expectancy } \\
\text { * Perceived Safety }\end{array}$ \\
\hline 13 & $\begin{array}{l}\text { Feedback is like Cinderella! The im- } \\
\text { portant role of feedback when hu- } \\
\text { mans and robots are working to- } \\
\text { gether in the factory }\end{array}$ & Stadler et al. & 2012 & $\begin{array}{l}\text { Workshop Po- } \\
\text { sition Paper }\end{array}$ & $\begin{array}{l}\text { * Feeling of Control } \\
\text { * Perceived Safety } \\
* \text { Trust }\end{array}$ \\
\hline 14 & $\begin{array}{l}\text { Input Modality and Task Complex- } \\
\text { ity: Do they Relate? }\end{array}$ & Stollnberger et al. & 2013 & $\begin{array}{l}\text { Conference } \\
\text { Proceedings }\end{array}$ & * Performance Expectancy \\
\hline 15 & $\begin{array}{l}\text { "The Harder it Gets": Explor- } \\
\text { ing the Interdependency of Input } \\
\text { Modalities and Task Complexity in } \\
\text { Human-Robot Collaboration }\end{array}$ & Stollnberger et al. & 2013 & \begin{tabular}{|l|} 
Conference \\
Proceedings
\end{tabular} & $\begin{array}{l}\text { * Perceived Workload } \\
\text { * Performance Expectancy } \\
\text { * Satisfaction } \\
\text { * Trust }\end{array}$ \\
\hline 16 & $\begin{array}{l}\text { The effect of input modalities and } \\
\text { different levels of task complexity } \\
\text { on feedback perception in a human- } \\
\text { robot collaboration task }\end{array}$ & Stollnberger et al. & 2012 & $\begin{array}{l}\text { Workshop Po- } \\
\text { sition Paper }\end{array}$ & * Satisfaction \\
\hline 17 & \begin{tabular}{|l} 
Combining Implicit and Explicit \\
Methods for the Evaluation of an \\
Ambient \\
play
\end{tabular} & Strasser et al. & 2012 & $\begin{array}{l}\text { Conference } \\
\text { Proceedings }\end{array}$ & * Performance Expectancy \\
\hline 18 & $\begin{array}{l}\text { "Contextual Researches" - Chal- } \\
\text { lenges and Approaches in the Fac- } \\
\text { tory Context }\end{array}$ & Weiss et al. & 2012 & $\begin{array}{l}\text { Workshop Po- } \\
\text { sition Paper }\end{array}$ & $\begin{array}{l}\text { * Perceived Workload } \\
* \text { Emotions and Feelings }\end{array}$ \\
\hline 19 & $\begin{array}{l}\text { Rethinking the Human-Agent Re- } \\
\text { lationship: Which Social Cues do do } \\
\text { Interactive Agents Really Need to } \\
\text { Have? }\end{array}$ & Weiss et al. & 2012 & Book Chapter & \\
\hline 20 & $\begin{array}{l}\text { Exploring Human-Robot Coopera- } \\
\text { tion Possibilities for Semiconductor } \\
\text { Manufacturing }\end{array}$ & Weiss et al. & 2011 & $\begin{array}{l}\text { Workshop Po- } \\
\text { sition Paper }\end{array}$ & * Perceived Usefulness \\
\hline 21 & $\begin{array}{l}\text { Research in the Semiconductor Fac- } \\
\text { tory: Insights into Experiences and } \\
\text { Contextual Influences }\end{array}$ & Wurhofer et al. & 2014 & $\begin{array}{l}\text { Conference } \\
\text { Proceedings }\end{array}$ & $\begin{array}{l}\text { * Stress } \\
\text { * Perceived Usefulness } \\
\text { * Satisfaction } \\
\text { * Trust } \\
\text { * Emotions and Feelings }\end{array}$ \\
\hline
\end{tabular}

Table 1. Overview of analyzed papers and associated factors

\subsection{Identified UX Factors}

Table 2 provides an overview of the identified UX factors. UX factors represent a component-oriented approach on UX, decomposing UX into specific aspects, which account for the users' experience when interacting with a system in a 
context. They represent measurable units of UX and thus support the operationalizability, measurability, and comparability of UX.

Taking a meta-perspective on our work, we found ten factors to be relevant for operators' experience in the semiconductor factory: perceived workload, stress, feeling of control, perceived usefulness, perceived ease of use, performance expectancy, satisfaction, perceived safety, trust, as well as emotions and feelings (see table 2 for an overview). Thereof, perceived workload was described in most of the papers ( 7 out of 10). Stress, perceived usefulness, and trust were mentioned in $60 \%$ of the papers (6 out of 10). Emotions and feelings were highlighted least often (3 out of 10). In the following, we outline those UX factors, which we have identified as relevant with regard to interactions in the semiconductor factory, in more detail.

\begin{tabular}{|c|c|c|}
\hline UX Factor & Description & Source \\
\hline Perceived Workload & $\begin{array}{l}\text { Cognitive effort required when interacting } \\
\text { with a system in order to solve a task }\end{array}$ & $\begin{array}{l}{[7],[18],[22],[28],} \\
{[32],[35],[41]}\end{array}$ \\
\hline Stress & $\begin{array}{l}\text { Workers' tension and perceived pressure } \\
\text { induced by the interaction }\end{array}$ & $\begin{array}{l}{[8],[23],[25],[27],} \\
{[31],[44]}\end{array}$ \\
\hline Feeling of Control & $\begin{array}{l}\text { Workers perceived influence on the sys- } \\
\text { tem's actions }\end{array}$ & {$[7],[30],[31]$} \\
\hline Perceived Usefulness & $\begin{array}{l}\text { Utility attributed to interacting with the } \\
\text { system }\end{array}$ & $\begin{array}{l}{[7],[23],[27],[32],} \\
{[40],[44]}\end{array}$ \\
\hline Perceived Ease of Use & $\begin{array}{l}\text { How easy the interface is to handle in the } \\
\text { interaction }\end{array}$ & {$[7],[17],[18],[23]$} \\
\hline Performance Expectancy & $\begin{array}{l}\text { Degree to which a worker believes that us- } \\
\text { ing the system will support his/her perfor- } \\
\text { mance }\end{array}$ & $\begin{array}{l}{[31], \quad[34],} \\
{[36]}\end{array}$ \\
\hline Satisfaction & $\begin{array}{l}\text { Workers' contentment with the interac- } \\
\text { tion }\end{array}$ & $\begin{array}{l}{[17], \quad[18], \quad[33],} \\
{[35],[44]}\end{array}$ \\
\hline Perceived Safety & $\begin{array}{l}\text { Workers' perception of the level of danger } \\
\text { when interacting with a system }\end{array}$ & {$[8],[28],[30],[31]$} \\
\hline Trust & $\begin{array}{l}\text { Extent to which the user feels confident } \\
\text { that the system will behave as intended }\end{array}$ & $\begin{array}{l}{[7],[17],[30],[32],} \\
{[35],[44]}\end{array}$ \\
\hline Emotions and Feelings & $\begin{array}{l}\text { Affective states of positive or negative va- } \\
\text { lence }\end{array}$ & {$[25],[41],[44]$} \\
\hline
\end{tabular}

Table 2. Identified UX factors and their frequencies $(\mathrm{N})$ with regard to publications

One aspect regularly mentioned by workers when interacting with systems in the factory is perceived workload ([7], [18], [22], [28], [32], [35], [41]), meaning the cognitive effort required when interacting with a system in order to solve a task. Attention and awareness are needed when interacting with a factory system; information overload increases the perceived workload.

Perceived workload is closely related to stress ([8], [23], [25], [27], [31], [44]), which reflects the workers' tension and perceived pressure induced by the interaction. Time pressure, shift cycles, problems with equipment and priorization of 
interfaces were often mentioned in relation to stress when interacting with the system.

Feeling of control ([7], [30], [31]) is another relevant UX factor, meaning the workers' perceived influence on the system's actions. Particularly, this factor is crucial in human-robot interaction, e.g., that the human stays in control of the robot. Further, unnecessary information on interfaces promotes a feeling of losing control.

Another UX factor crucial in the factory is perceived usefulness ([7], [23], [27], [32], [40], [44]), which denotes the utility attributed to interacting with the system. In the factory, a system is perceived as useful and supportive if it improves, for example, the workers' efficiency or effectiveness. Otherwise, if a system works slow or even freezes sometimes, it is perceived as a hindrance regarding workers' performance.

Perceived ease of use ([7], [17], [18], [23]), i.e., how easy the interface is to handle in the interaction, is closely related to learnability and intuitiveness/complexity of the system. Information overload and slow performance of interfaces in the factory are considered as the main problems when using them. Such problems are often mentioned as a source of stress for workers.

Performance Expectancy ([31], [34], [35], [36]) means the degree to which a worker believes that using the system will support his/her performance. In the factory context, the expected performance is often decreased due to external factors like technical problems, bad work organization, or equipment related issues such as slow delivery of lots or too many equipment items in service.

We further identified satisfaction ([17], [18], [33], [35], [44]), i.e., the contentment with the interaction, as a UX factor. Workers are satisfied either when they consider their performance as being good, or when they get positive feedback regarding their performance from others (i.e., colleagues or superiors). The more difficult a task, the more satisfied they are.

Another UX factor is perceived safety ([8], [28], [30], [31]), describing the workers' perception of the level of danger when interacting with a system. This aspect of UX is especially relevant when dealing with robots. For example, certain security mechanisms (e.g., emergency stop button) or displaying the robot's current and next state convey a feeling of safety in human-robot interaction.

Trust ([7], [17], [30], [32], [35], [44]) is also an important issue regarding workers' experience at the factory. With trust we refer to the extent to which the user feels confident that the system will behave as intended. Trust is closely related to perceived safety and the feeling of control. Reliable and error-free system processes as well as feedback modalities that inform about the system's current state might help to improve trust towards the system.

Emotions and feelings, i.e., affective states of positive or negative valence, further shape the workers' daily experience in the factory. Negative emotional experiences we identified were anger, fear, and frustration ([25], [41], [44]). Regarding anger, workers often mention usability and work organization as a cause. For example, workers are bothered when the machines are difficult to handle, or when action space is limited. Similarly, frustration is, for example, 
related to slow response time of the interfaces or information overload and thus closely related to stress. Fear is often associated with human-robot interaction, as workers are afraid of being replaced by robots. Positive emotions mentioned with regard to factory work are joy, fun, and pride [44]. Overall, production tasks are rather linked to negative emotions, whereas administrative activities are experienced rather positive, fostering emotions like fun, joy or pride.

\subsection{Influences on UX}

Influences on $U X$ can arise from characteristics of the user, the system, or the context (e.g., [13], [20]). In our work, we differentiate influences on UX that origin from the user (individuell influences), from the system (system influences), and from the context (contextual influences).

Individual influences (e.g., [7], [8], [17], [26], [32], [31], [35], [36], [44]). Motivation can be considered as a characteristic of the worker influencing his or her experience. Sources for motivation are, for example, an increase of productivity despite having a lot of equipment down, working passionately for a common goal, or getting invited for a coffee to speak about the company. Further, the workers' attitude towards the system to interact with is crucial. Another influence on the experienced interaction is the workers' general well-being. Pre-experience, i.e., already gained know-how, was also found to influence the workers experience, similar to reflexivity (in the sense of conscious retrieval of knowledge and competences). Further, the workers' flexibility as well as their routines influence their UX.

System influences (e.g., [7], [17], [26], [28], [32], [30], [31], [33], [34], [35], [36], $[44])$. In the factory, the system's appearance in the sense of aesthetics and form as well as visibility of information and transparency of actions was found to influence the workers' experience. Autonomy, adaptivity, as well as flexibility of the system also shape UX. Consistency of the system's procedures, actions, or representations is important as well as the persuasiveness of the system in the sense of guiding the user in his/her actions or tasks. Reliability of the system in the sense of trustworthiness and functionality influences the workers' experience. Further, the complexity and intuitiveness of the system are crucial. This includes issues like training needed to interact with the system, understandability, or learnability. Efficiency (e.g., the system's performance) and effectiveness (e.g., error rate) are further properties of the system affecting UX.

Contextual influences (e.g., [8], [18], [25], [26], [27], [30], [35], [36], [44]). With regard to the the physical context, noise was found to be characteristic in the factory, representing a physical constraint and an influence on the workers' experience. Light as well as temperature (e.g., heat) represent further characteristics of the physical context of the factory. The special clothing required 
especially in the cleanroom is another constraint, needed to minimize contamination which has to be kept as low as possible (especially in the cleanroom). Additionally, the action space (i.e., amount of space to walk around) shapes the workers' experience.

Additionally, the workers? social context affects their experience, for instance, interpersonal reliability, i.e., the trustworthiness of colleagues. Further, equal treatment in the sense that everybody is treated in the same way by colleagues and superiors is another influence factor. Appreciation, e.g., positive feedback from colleagues or superiors, is also crucial for workers, shaping their experience. Finally, hierarchy, meaning the fulfilling of formal roles and associated expectations, affects UX.

\section{Discussion}

In the light of the factory being a challenging and hardly investigated context in HCI, the main intention of our work was to identify and collect UX factors as well as influences on UX in order to contribute a comprehensive picture of UX in the factory.

With the meta-analysis presented in this paper, we aim to create awareness that UX in factories is worthwhile to investigate and design for. Therefore, we illustrate differentiated needs and sources for the design of appropriate interactive systems. We provide reference points for designers which they can draw on when conceptualizing and developing systems for the factory context that support a positive experience at work. In the following, we discuss the main issues we were confronted with when researching UX in a factory context.

Restricted accessibility and complexity of the factory context. A factory presents a research context which is difficult to access in terms of sampling (i.e., access to the people who are in the focus of research) as well as physical presence of the researcher (i.e., access to specific areas in the factory). The first and foremost demand when doing research in this context is not to impact work practices [41]. This means that the factory's goals of error free production, efficiency of production processes, as well as cleanroom requirements (e.g., specific clothing) must not be impaired. Next to accessibility, the complexity of the factory environment (in terms of work practices, processes, and equipment) represents a hurdle for researchers. From our experience, basic knowledge regarding practices, processes, and equipment is necessary to conduct studies in this context (e.g., in order to have the "right" vocabulary in interviews).

The restricted accessibility and complexity of the factory context may be one of the reasons why UX research in this context is scarce [2]. Thus, with our contribution, i.e., factors accounting for workers' experience in the factory, we provide insights into a very restricted environment, allowing designers and researchers to better understand this context.

Designing for $\boldsymbol{U X}$ in the factory. According to Kaasinen et al. [16], the core of experience design is the definition of UX goals, i.e., defining what experience 
to design for. With regard to industrial contexts, where various stakeholders are involved, concrete and shared UX goals are crucial to ensure a clear conception of the targeted experience and to support keeping UX in focus. We think that the UX factors we introduced in this work can be employed as a basis for setting UX goals for design in the factory context. This would be especially valuable with regard to factories of the future and future workplace designs.

We are aware that narrowing down the workers' experience to a list of UX factors is linked to specific drawbacks, rooted in the discussion of holistic versus reductive approaches on UX [5]. In particular, the uniqueness and situatedness of experience as stated by proponents of the holistic perspective (e.g., [20]) is lost. Following Redström [29], design should create and optimize a user's experience on the basis of predictions. Thus, such reductions seem to be necessary at this stage to break down empirical insights into concrete suggestions for the design. We consider our UX factors as such leverage points for interaction design. Nevertheless, we want to stress that designs should provide enough space for the user to act and improvise [29], ensuring that we do not lose the holistic viewpoint on experience.

UX Methodology. Throughout our work, we applied a range of methods, both qualitative and quantitative. In relation to this approach, we tried to consider UX from a holistic as well as reductionistic perspective. At specific stages of the research process (e.g., at the beginning of the project), it was meaningful to take a holistic perspective on UX, not narrowing it down to specific factors but trying to comprehend specific phenomena in as much detail as possible [20]. At other stages (e.g., after a basic understanding of the factory context was gathered), it was valuable to take on a reductionistic perspective in order to investigate very specific research questions or generalize findings [12].

Overall, our approach of taking different perspectives at different stages within a research process provided us with a comprehensive picture on workers' experiences in a factory. In our opinion, this approach supported us in uncovering otherwise (i.e., when just adopting one perspective) hidden factors. We think that such an approach has not been applied so far in this domain and therefore represents a methodological step forward towards studying UX in the factory.

$\boldsymbol{U} \boldsymbol{X}$ Factors. Regarding the identified factors, some of them may be less surprising, given the context of a production environment, (e.g., perceived workload, stress, performance expectancy). Others, however, are more surprising (e.g., emotional experiences, such as fun, anger, or pride), pointing out possibilities for design that may not be initially thought of in this context. For example, we found that negative emotions like anger, fear or frustration are much more prominent regarding workers' experiences than positive emotions like joy or fun.

An implication of this finding may be to focus more specifically on positive experiences in future designs, wherefore we provided indications of what accounts for positive experiences in the factory in our work. Similarly, the results help us understand why designs may lead to different actions than imagined or intended (e.g., technology appropriation [9]). Thereby, the complexity is even 
increased through the interplay of the various factors and aspects. This poses serious challenges especially to the design of interactive systems, as it is difficult to decide what exactly to design for. Nevertheless, being aware of the situated nature of interactions and the range of experiences that may occur, as well as what may influence them, will help to explicitly decide for or against certain aspects, depending on their likelihood of appearance or relevance.

Valuing $\boldsymbol{U} \boldsymbol{X}$ research. An important aspect for our research was to show the relevance of UX research in the factory context. In particular, the stakeholders involved in our research (e.g., operators, maintainers, shift leads, management) learned about the value of UX and UX research. We think that is important to understand that positive experiences have a positive effect on workers (e.g., are for example related to efficiency, work satisfaction, or pride), which in turn provides competitive advantage in an industrial context [38].

In our experience, time was crucial for understanding the importance of UX. With progressing time, i.e., over the years, the stakeholders saw increasing value of our research. This could be due to the fact that at the beginning our scientific approach was not tangible for the stakeholders. As Ardito et al. [2] argue, scientific research and methods should be translated into something that makes sense for companies. In order to provide an understanding of what UX in a factory context is, we think that a list of dedicated factors accounting for the workers' experience in daily work is helpful. Such a list of factors represents something that is tangible and meaningful for companies, especially when illustrated by examples from daily worklife. Moreover, these UX factors provide a better contextual understanding of the factory.

Further, the active involvement of practitioners in the overall research process is also important [2]. Although not always possible in practice, we saw that presenting the results to the stakeholders and discussing them with them increased the acceptance and openness towards UX research in the factory.

According to Väätäjä et al. [38], showing the value of UX by measures is important. However, the question is what to measure, i.e., which factors account for UX in the context of production environments. We think that our paper represents a valuable contribution to this question, as it lists a range of factors which account for the workers' experience in a factory. By quantifying (i.e., measuring) specified factors, comparisons can be made and trends can be detected. Thus, UX factors provide an anchor for quantifying and improving workers' experience.

Specific use case. The described study environment represents a very specific use case. Thus, the factors presented above are subject to limitation, as they have been collected in a specific factory on basis of case studies, or within studies in a laboratory where the production context was simulated. Contextual conditions like light, temperature, noise, clothing might vary from factory to factory in their specific shape. Nevertheless, it is likely that the described influence factors are relevant in other factory environments as well, even if their manifestations differ. 
With regard to UX factors, we assume a similar situation: differences to other production environments may primarily affect the degree of occurrence rather than the question whether the factors play a role at all.

An advantage due to the specific and single use case is the comparability of results. As all stakeholders involved in our studies work in the same factory, differences regarding their experience cannot be due to differences in the work environment (which could be the case if results from different factories are compared). Of course, the set of factors may be extended through further studies in other production environments.

Opportunities and Challenges. Critically reflecting on our work, it represents an exception as we had the opportunity to conduct studies for more than five years in a sensitive context which is challenging and hard to access. Thus, our research advanced from initial studies aiming to get to know the context to very specific studies investigating defined factors in detail.

A particular challenge we were confronted with was to gain the trust of the responsible stakeholders in the factory. This was especially hard at the beginning, when the stakeholders were skeptical about research in this challenging context. In particular, workers had concerns and doubts about anonymity of their statements and that superiors would be informed about their opinions. Therefore, it was especially important to emphasize anonymity and discretion whenever getting in contact with stakeholders. Further, we had the impression that the closer the contact was (e.g., individual interviews), the more open the stakeholders were towards the researchers. Next to closeness, time was a factor influencing openness of stakeholders. With progressing time, trust and openness towards the researchers increased and made it possible for researchers and stakeholders to work together closely.

Based on the insights gained within the last five years, we further developed and shaped our research. For example, we recognized that workers' experiences and attitudes are closely linked to specific incidents (e.g., the deployment of a robot), and that deeper investigation of such incidents provides knowledge about the dynamics and changes of workers' experiences. Therefore, we retrospectively investigated how workers experienced the deployment of a robot [21] and put a focus on the temporal transitions of workers' experiences in this context [43]. Such insights enrich the understanding of the UX factors in terms of comprehensively looking at experiential processes of workers in the factory.

\section{Conclusion}

This paper presents an analysis of UX in human-work interactions, which is based on several studies in the context of a semiconductor factory. Factors relevant in this context were identified and clustered to reveal the multiple facets of user experiences and influences on this experience. We presented UX factors occurring in the factory, ranging from stress, performance expectancy, trust, and satisfaction, to joy, pride, fear, and anger. Those factors are influenced by user 
characteristics, such as the user's attitude, well-being, flexibility, or routines. Furthermore, system aspects affect the users' experiences (e.g., complexity, appearance, visibility, accessibility, or persuasiveness). Contextual specifics may also influence human-work interactions, i.e., the physical context (e.g., noise, light, clothing, or action space) and the social context (e.g., interpersonal reliability, equality, or appreciation). Focusing on these factors also in the design of human-work interactions is a promising approach to improve users' experience at work, which eventually results in motivation and well-being at work.

For future work, we plan to extend our insights with studies from other factories. Similarities and differences should be explored across different factories in order to find out which factors are more or less stable when the specific environment changes. Further, we want to put a focus on the interrelations and dynamics of selected UX factors, which might be helpful for future factory and workplace designs. Finally, we aim to advance our research on temporal transitions of workers' experiences by studying newly deployed systems in the course of time.

\section{Acknowledgments}

The financial support by the Austrian Federal Ministry of Science, Research and Economy and the National Foundation for Research, Technology and Development is gratefully acknowledged (Christian Doppler Laboratory for "Contextual Interfaces"). Special thanks is dedicated to the researchers involved in the qualitative analysis: Axel Baumgartner, Elke Beck, Ulrike Bruckenberger, Roland Bucher, Alina Krischkowsky, Susanne Stadler, and Barbara Weichselbaumer.

\section{References}

1. Alben, L.: Quality of experience: defining the criteria for effective interaction design. Interactions 3(3), 11-15 (1996)

2. Ardito, C., Buono, P., Caivano, D., Costabile, M.F., Lanzilotti, R.: Investigating and promoting $\{\mathrm{UX}\}$ practice in industry: An experimental study. International Journal of Human-Computer Studies 72(6), 542 - 551 (2014), interplay between User Experience Evaluation and System Development

3. Bargas-Avila, J.A., Hornbaek, K.: Old wine in new bottles or novel challenges: a critical analysis of empirical studies of user experience. In: Proceedings of the 2011 annual conference on Human factors in computing systems. pp. 2689-2698. CHI '11, ACM, New York, NY, USA (2011)

4. Björndal, P.S., Ralph, M.B.: On the handling of impedance factors for establishing apprenticeship relations during field studies in industry domains. In: Proceedings of the 8th Nordic Conference on Human-Computer Interaction: Fun, Fast, Foundational. pp. 1107-1112. NordiCHI '14, ACM, New York, NY, USA (2014)

5. Blythe, M., Hassenzahl, M., Law, E., Vermeeren, A.: An analysis framework for user experience (ux) studies: a green paper. In: Paper presented at the Proceedings of the 'Towards a UX Manifesto workshop' at HCI 2007. Lancaster, UK (2007)

6. Brown, J.A.: The social psychology of industry. Penguin Books (1954) 
7. Buchner, R., Kluckner, P.M., Weiss, A., Tscheligi, M.: Assisting maintainers in the semiconductor factory: Iterative co-design of a mobile interface and a situated display. In: Proceedings of the 12th International Conference on Mobile and Ubiquitous Multimedia. pp. 46:1-46:2. MUM '13, ACM, New York, NY, USA (2013)

8. Buchner, R., Wurhofer, D., Weiss, A., Tscheligi, M.: Robots in time: How user experience in human-robot interaction changes over time. In: Herrmann, G., Pearson, M., Lenz, A., Bremner, P., Spiers, A., Leonards, U. (eds.) Social Robotics, Lecture Notes in Computer Science, vol. 8239, pp. 138-147. Springer International Publishing (2013)

9. Dix, A.: Designing for appropriation. In: Proceedings of the 21st British HCI Group Annual Conference on People and Computers: HCI... but not as we know it-Volume 2. pp. 27-30. British Computer Society (2007)

10. Fallman, D., Kruzeniski, M., Andersson, M.: Designing for a collaborative industrial environment: The case of the abb powerwall. In: Proceedings of the 2005 Conference on Designing for User eXperience. DUX '05, AIGA: American Institute of Graphic Arts, New York, NY, USA (2005)

11. Grill, T., Reitberger, W., Obrist, M., Meschtscherjakov, A., Tscheligi, M.: The christian doppler laboratory on contextual interfaces. In: Proceedings of the First International Joint Conference on Ambient Intelligence. pp. 325-332. AmI'10, Springer-Verlag, Berlin, Heidelberg (2010)

12. Hassenzahl, M., Tractinsky, N.: User experience - a research agenda. Behaviour \& Information Technology 25(2), 91-97 (2006)

13. Hassenzahl, M., Diefenbach, S., Göritz, A.: Needs, affect, and interactive products - facets of user experience. Interact. Comput. 22(5), 353-362 (Sep 2010)

14. Heyer, C.: Investigations of ubicomp in the oil and gas industry. In: Proceedings of the 12th ACM International Conference on Ubiquitous Computing. pp. 61-64. UbiComp '10, ACM, New York, NY, USA (2010)

15. IEE Colloquium: IEE Colloquium on 'HCI: Issues for the Factory' (Digest No.047). IET (Feb 1991)

16. Kaasinen, E., Roto, V., Hakulinen, J., Heimonen, T., Jokinen, J.P., Karvonen, H., Keskinen, T., Koskinen, H., Lu, Y., Saariluoma, P., et al.: Defining user experience goals to guide the design of industrial systems. Behaviour \& Information Technology (ahead-of-print), 1-16 (2015)

17. Kluckner, P.M., Buchner, R., Weiss, A., Tscheligi, M.: Repair now: Collaboration between maintainers, operators and equipment in a cleanroom. In: Proceedings of the ACM conference on computer supported cooperative work. pp. 143-146. CSCW2012, ACM, New York, NY, USA (2012)

18. Kluckner, P.M., Buchner, R., Weiss, A., Tscheligi, M.: Collaborative reporting tools: An analysis of maintainance activites in a semiconductor factory. In: Collaboration Technologies and Systems (CTS). pp. 508-515 (2013)

19. Law, E.L.C., van Schaik, P.: Editorial: Modelling user experience - an agenda for research and practice. Interact. Comput. 22(5), 313-322 (2010)

20. McCarthy, J., Wright, P.: Technology as experience. Interactions (2004)

21. Meneweger, T., Wurhofer, D., Fuchsberger, V., Tscheligi, M.: Working together with industrial robots: Experiencing robots in a production environment. In: Proceedings of the 24th IEEE International Symposium on Robot and Human Interactive Communication (RO-MAN) (2015)

22. Meschtscherjakov, A., Kluckner, P.M., Pöhr, F., Reitberger, W., Weiss, A., Tscheligi, M., Hohenwarther, K.H., Osswald, P.: Ambient persuasion in the factory: The case of the operator guide. In: IEEE (ed.) ASCM2011: 22nd annual IEEE/SEMI Advanced Semiconductor Manufactoring. pp. 1-6 (2011) 
23. Meschtscherjakov, A., Reitberger, W., Pöhr, F., Tscheligi, M.: The operator guide: An ambient persuasive interface in the factory. In: First International Joint Conference on Ambient Intelligence (Malaga, Spain, November 10-12, 2010) (2010)

24. Mirnig, A.G., Meschtscherjakov, A., Wurhofer, D., Meneweger, T., Tscheligi, M.: A formal analysis of the iso 9241-210 definition of user experience. In: Proceedings of the 33rd Annual ACM Conference Extended Abstracts on Human Factors in Computing Systems. pp. 437-450. CHI EA '15, ACM, New York, NY, USA (2015)

25. Obrist, M., Reitberger, W., Wurhofer, D., Förster, F., Tscheligi, M.: User experience research in the semiconductor factory: a contradiction? In: Proceedings of the 13th IFIP TC 13 international conference on Human-computer interaction Volume Part IV. pp. 144-151. INTERACT'11, Springer-Verlag, Berlin, Heidelberg (2011)

26. Osswald, S., Buchner, R., Weiss, A., Tscheligi, M.: Designing for the factory: Wearable experience prototyping for idea communication. In: Extended Abstracts of the ACM Conference on Designing Interactive Systems. DIS'12, Newcastle, UK (2012)

27. Osswald, S.a.: Using participatory design to investigate technology usage in the cleanroom of a semiconductor factory. In: Workshop The Message in the Bottle: "Best Practices for Transferring the Knowledge from Qualitative User Studies" at DIS'12 (2012)

28. Osswald, S., Weiss, A., Tscheligi, M.: Designing wearable devices for the factory: Rapid contextual experience prototyping. In: Collaboration Technologies and Systems (CTS), 2013 International Conference on. pp. 517-521. IEEE (2013)

29. Redström, J.: Towards user design? on the shift from object to user as the subject of design. Design studies 27(2), 123-139 (2006)

30. Stadler, S., Mirnig, N., Weiss, A., Tscheligi, M.: Feedback is like cinderella! the important role of feedback when humans and robots are working together in the factory. In: Workshop "Feedback in HRI" at RO-MAN 2012 (2012)

31. Stadler, S., Weiss, A., Mirnig, N., Tscheligi, M.: Anthropomorphism in the factory - a paradigm change? In: HRI '13: Proceedings of the 8th ACM/IEEE International Conference on Human Robot Interaction. pp. 231-232 (2013)

32. Stadler, S., Weiss, A., Tscheligi, M.: I trained this robot: The impact of preexperience and execution behavior on robot teachers. In: 23rd IEEE International Symposium on Robot and Human Interactive Communication (2014)

33. Stollnberger, G., Weiss, A., Tscheligi, M.: The effect of input modalities and different levels of task complexity on feedback perception in a human-robot collaboration task. In: Workshop "Feedback in HRI" at RO-MAN 2012. Paris, France (2012)

34. Stollnberger, G., Weiss, A., Tscheligi, M.: Input modality and task complexity: Do they relate? In: HRI '13: Proceedings of the 8th ACM/IEEE International Conference on Human Robot Interaction. pp. 233-234 (2013)

35. Stollnberger, G., Weiss, A., Tscheligi, M.: "the harder it gets": Exploring the interdependency of input modalities and task complexity in human-robot collaboration. In: Proceedings of the 22nd IEEE International Symposium on Robot and Human Interactive Communication (RO-MAN)). pp. 264-269. IEEE (2013)

36. Strasser, E., Weiss, A., Grill, T., Osswald, S., Tscheligi, M.: Combining implicit and explicit methods for the evaluation of an ambient persuasive factory display. In: AmI2012: Proceedings of the 6th European Conference on Ambient Intelligence. pp. 113-128. Springer Berlin/Heidelberg (2012)

37. Tscheligi, M., Meschtscherjakov, A., Weiss, A., Wulf, V., Evers, V., Mutlu, B.: Exploring collaboration in challenging environments: From the car to the factory and beyond. In: Proceedings of the ACM 2012 Conference on Computer Supported 
Cooperative Work Companion. pp. 15-16. CSCW'12, ACM, New York, NY, USA (2012)

38. Väätäjä, H., Seppänen, M., Paananen, A.: Creating value through user experience: a case study in the metals and engineering industry. International Journal of Technology Marketing 9(2), 163-186 (2014)

39. Weed, M.: "Meta Interpretation": A method for the interpretive synthesis of qualitative research. Forum Qualitative Sozialforschung / Forum: Qualitative Social Research 6(1) (2005), http://www.qualitativeresearch.net/index.php/fqs/article/view/508

40. Weiss, A., Buchner, R., Fischer, H., Tscheligi, M.: Exploring human-robot cooperation possibilities for semiconductor manufacturing. In: International Workshop on Collaborative Robots and Human Robot Interaction. pp. 173-177 (2011)

41. Weiss, A., Kluckner, P.M., Buchner, R., Tscheligi, M.: Contextual researches challenges and approaches in the factory context. In: Workshop at CSCW $2012-$ Exploring collaboration in challenging environments: From the car to the factory and beyond (2012)

42. Weiss, A., Tscheligi, M.: Rethinking the human-agent relationship: Which social cues do interactive agents really need to have? In: Believable Bots, pp. 1-28. Springer (2012)

43. Wurhofer, D., Meneweger, T., Fuchsberger, V., Tscheligi, M.: Deploying robots in a production environment: A study on temporal transitions of workers' experiences. In: Proceedings of Interact 2015, Part III. pp. 203-220. Springer (2015)

44. Wurhofer, D., Buchner, R., Tscheligi, M.: Research in the semiconductor factory: Insights into experiences and contextual influences. In: Proceedings of 7 th International Conference on Human System Interaction (HSI). pp. 129-134 (2014) 